\title{
A Bioética e o Problema do Acesso À ATENÇÃo EM SAÚdE ${ }^{(*)}$
}

Osmir Antonio Globekner (**)

\section{RESUMO}

Trata-se neste estudo da contribuição da reflexão bioética ao problema do acesso à atenção em saúde. Parte-se do reconhecimento de um inevitável panorama de escassez dos recursos materiais e humanos, resultando em incontornáveis escolhas alocativas a serem assumidas pela sociedade, as quais hão de ser informadas por critérios ético-jurídicos. Descreve-se, exemplificativamente, o pensamento bioético desenvolvido por alguns autores referenciais - escolhidos de maneira aleatória, dos Estados Unidos, de Portugal, da Espanha e da América Latina -, como forma de ilustrar a abordagem do tema tanto na tradição liberal, de alocação pelo mercado, como na tradição social, de alocação por meio da despesa pública. Busca-se, por fim, a aproximação das abordagens visando à obtenção de um tratamento uniforme do problema sob o ponto de vista bioético. Paralelamente, procura-se identificar o tema do acesso em saúde à pauta "bioética".

\section{Palavras-chave}

Atenção à Saúde; Acesso aos Serviços de Saúde; Bioética; Equidade; Recursos Financeiros.

$\left(^{*}\right)$ Trabalho apresentado no XVII Congresso Nacional do Conselho Nacional de Pesquisa e PósGraduação em Direito (CONPEDI), realizado de 20 a 21 de novembro de 2008, em Brasília/DF, com alterações.

${ }^{\left({ }^{*}\right)}$ Mestrando em Direito Público na Faculdade de Direito da Universidade Federal da Bahia (FD/ UFBA), especialista em Direito Sanitário pela Faculdade de Saúde Pública da Universidade de São Paulo (FSP/USP), bacharel em Direito (UESC) e engenheiro químico (FEC/Unicamp). E-mail: <osmirag@uol.com.br>. Recebido em 11.12.08. Revisado em 06.05.09. Aprovado em 26.05.09. 


\section{ABSTRACT}

This study deals with the contribution of the bioethical reflection to the health care access problem. It starts from the recognition of the shortage of material and human resources that result in choices of allocation to be made by society, which should be guided by ethical and legal criterions. The study describes, for purposes of illustration, the bioethical thought developed by some referential authors from United States, Spain, Portugal and Latin America, which were chosen at random, just with the aim at illustrating the approach of the matter either in the liberal tradition of trade allocation as well as in the social tradition of public expenses allocation. At last, the study searches for some relations between these two approaches in order to find out a common treatment of the problem under a bioethical standpoint. The study is also directed to demonstrate that health care access issue is related to the bioethics.

\section{Keywords}

Accessibility; Bioethics; Equity; Financial Resources; Health Care; Health Services.

O tema da saúde raramente está presente no debate bioético. Este privilegia tãosomente as situações extremas como os nascimentos 'artificiais', os transplantes de órgãos, as condições de sobrevivência terminal, descuidando-se do fato de que a saúde e a doença são para todos um campo universal de experiência, de reflexão, e até de escolhas morais. À saúde frequentemente é negado o título de nobreza como objeto da ética e, na melhor das hipóteses, Ihe é atribuído apenas o valor (que para alguns é considerado filosoficamente irrelevante e intelectualmente plebeu) de "questão social".(1)

Los problemas vinculados con la salud colectiva junto a los factores que la condicionan debieran estar en el centro de la reflexión bioética, para que esta disciplina de corta historia no se transforme en algo desvinculado de la realidad que envuelve a millones de hombres. ${ }^{(2)}$

\section{INTRODUÇÃO}

Ao se buscar a efetivação do direito à saúde no onipresente panorama da escassez de recursos, alocações ou escolhas ocorrerão, posto que mesmo

(1) BERLINGUER, Giovanni. Ética da saúde. São Paulo: Hucitec, 1996. p. 16.

(2) BERGEL, Salvador Darío. Bioética y el derecho de acceso a los medicamentos. Revista de Direito Sanitário, São Paulo, v. 7, n. 1-3, p. 119, 2006. 
a simples satisfação de determinada necessidade implicará inevitavelmente, diante dos custos de oportunidade, que outras tantas deixem de ser atendidas.

Torna-se relevante, nesse contexto, do ponto de vista ético-jurídico, perquirir o lugar e o mérito dessas escolhas, quer sejam assumidas pela sociedade como decisões alocativas, quer não, bem como os fatores que determinam aquelas ou os critérios que orientam estas.

Nesse escopo, coloca-se como objeto do presente estudo perscrutar alguns elementos que a abordagem bioética pode aportar ao debate éticojurídico sobre as escolhas ou decisões alocativas no campo sanitário e, por via de consequência, identificar a pertinência, à pauta da discussão bioética, do problema do acesso à atenção em saúde.

Assim, a proposta é analisar alguns discursos originados na reflexão bioética, nos Estados Unidos, através do pensamento de Tom L. Beauchamp e James F. Childress; em Portugal e na Espanha, por meio do pensamento de Maria do Céu Patrão Neves e Ángel Puyol González respectivamente, e, na América Latina por intermédio do pensamento de Miguel Kottow, no Chile, e Fermin Roland Schramm e Volnei Garrafa, no Brasil. Não se pretende aqui uma análise exaustiva, senão uma amostragem aleatória, com fins ilustrativos, do pensamento bioético desenvolvido em tais países. Embora aleatória, tratase de amostragem significativa, dado o caráter referencial desses autores no campo analisado.

O objetivo com tal análise é o de sugerir uma relativização de duas dicotomias identificadas no tratamento do tema.

A primeira se refere à que separa os fundamentos dos sistemas de alocação de tradição liberal, através do mercado, dos fundamentos dos sistemas de alocação de tradição social, por meio da despesa pública.

A segunda dicotomia é a que aparta o que se convencionou chamar de "bioética das situações emergentes" da "bioética das situações persistentes".

\section{O PROBLEMA DO ACESSO NOS ESTADOS UNIDOS (TOM L. BEAUCHAMP E JAMES F. CHILDRESS E RONALD DWORKIN)}

O problema do acesso à atenção à saúde, obviamente, não está ausente na discussão bioética de inspiração clássica. Beauchamp e Childress ${ }^{(3)}$, ao tratarem do Princípio da Justiça no capítulo 7 de "Principles of Biomedical Ethics", abordam a questão do direito à atenção em saúde em face das políticas públicas de saúde. A questão, no contexto norte-americano, é

(3) BEAUCHAMP, Tom L.; CHILDRESS, James F. Principles of biomedical ethics. 6th ed. New York: Oxford University Press, 2009. 
traduzida em termos de acesso ao seguro-saúde e dos bens e serviços relacionados à saúde, os quais, por sua natureza, hão de ser compartilhados na sociedade:

The primary economic barrier to health care access in many countries - most visibly the United States - is the lack of adequate insurance. Close to 50 million U.S. citizens (approximately $18 \%$ of the nonelderly population) lack health insurance of any kind. Inadequate insurance affects persons who are uninsured, uninsurable, underinsured, or only occasionally insured. [...] In many other countries the primary barriers to both health and health care are poverty and limited government resources. Problems of justice are very different in different parts of the world. ${ }^{(4)}$

Na sequência, os autores, reconhecendo que os problemas de justiça são diferentes em diversas partes do mundo, com causas e formas de abordagem também distintas, apontam, nos Estados Unidos, situações de injustiça que emergem de um financiamento regressivo do seguro-saúde, em que famílias de mais baixa renda pagam prêmios comparáveis ou superiores aos das famílias de mais alta renda, por coberturas muitas vezes inferiores.

O problema, naquele país, é parcialmente atribuído à relevância da participação dos empregadores no financiamento, pois grandes empregadores podem proporcionar melhores coberturas e a custo mais baixo do que pequenos empregadores, em virtude do seu maior poder de negociação e também do gozo de vantagens fiscais. Essa desigualdade no acesso agravase ainda mais se se considerarem os não-protegidos por coberturas coletivas, para os quais os preços dos prêmios se tornam dramaticamente elevados, para não citar as famílias e os indivíduos sem qualquer cobertura.

Beauchamp e Childress indicam que a consciência dessa desigualdade no acesso fez emergir um consenso social nos Estados Unidos em torno da necessidade de que políticas nacionais de saúde levem em conta a distribuição e o racionamento de bens e serviços de saúde compartilhados pela sociedade e de que se possam favorecer condições mais equânimes para que todo cidadão seja capaz de assegurar a si mesmo o acesso à atenção em saúde, incluindo-se aí a adequada cobertura securitária. Os autores afirmam, entretanto, que esse consenso é tênue diante da ampla

(4) "A barreira econômica primária para o acesso à atenção em saúde em muitos países - mais visivelmente nos Estados Unidos - é a deficiência da cobertura securitária. Cerca de 50 milhões de cidadãos norte-americanos (aproximadamente $18 \%$ da população não idosa) carecem, em alguma medida, de cobertura securitária para a saúde. A cobertura inadequada abrangendo da ausência de cobertura à impossibilidade de cobertura, cobertura insuficiente ou cobertura apenas ocasional. [...] Em muitos outros países as barreiras primárias à saúde e à atenção à saúde são a pobreza e a limitação dos recursos governamentais. Os problemas de justiça são distintos em diferentes partes do mundo." BEAUCHAMP, Tom L.; CHILDRESS, James F. op. cit. p. 258, tradução nossa. 
discordância existente em relação à extensão das soluções propostas, ao papel do governo nessas soluções e à forma de financiá-las.

A consideração de um "direito à atenção em saúde" aparece, portanto, nesse discurso, apenas de modo indireto. No contexto liberal, este não se constituirá em um direito em si, de caráter abrangente e integrante do plexo de direitos sociais do cidadão, com prestações a serem providas, fundamentalmente, pelo Estado, senão que será deduzido com base em raciocínio derivado de duas linhas principais de argumentos ${ }^{(5)}$ : 1) os ligados à proteção social coletiva; 2) os ligados à igualdade de oportunidades.

$\mathrm{Na}$ primeira linha de argumentos, tem-se a consideração de que a saúde é concernente à proteção coletiva, pois afeta a sociedade da mesma forma que o crime, a poluição ambiental, as catástrofes naturais e outros riscos coletivos, os quais ordinariamente merecem a proteção social do Estado Liberal. Assim, por essa linha argumentativa, justificar-se-ia uma assistência pública em cuidados críticos de saúde. A par disso, o fato de a sociedade investir ações e recursos coletivos em programas públicos de saúde (existentes em qualquer sociedade) ou na formação de médicos e na pesquisa médica, através de fundos públicos, constituiria um fundamento para que o retorno desse investimento à sociedade ocorresse, também, por meio de uma atenção mínima à saúde de caráter público.

A segunda linha de argumento invoca a regra da oportunidade justa. A necessidade de justiça nas instituições sociais deve fazer com que se busque contrabalançar os déficits de oportunidade causados por circunstâncias imprevisíveis fora do controle dos indivíduos, tais como acidentes e incapacidades geradas pelas próprias doenças e que justificariam o uso de recursos sociais para restabelecer o equilíbrio de oportunidades.

Os autores alinham diferentes teorias da justiça: a utilitarista, a libertarista, a comunitarista e a igualitarista. Em referência a elas, a interpretação mais estrita de igualdade no acesso significaria que cada cidadão tenha igual acesso a cada bem ou serviço de saúde que esteja disponível a qualquer outro cidadão. Concluem os autores, entretanto, que tal objetivo seria utópico no atual sistema econômico e que um direito mais aceitável, apto a promover uma conciliação, entre teorias mais e menos da igualdade, seria o "direito a um mínimo decente de atenção em saúde"(6). Na verdade, poderse-ia identificar tal conceito ao de "mínimo existencial", defendido, entre todos, para justificar a limitação das demandas a serem atendidas no contexto dos limites de atuação do Estado de Bem-Estar Social.

Beauchamp e Childress consideram ainda a possibilidade de perda de tal direito em decorrência de um comportamento social inadequado ${ }^{(7)}$.

(5) Arguments supporting rights to health care. BEAUCHAMP, Tom L.; CHILDRESS, James F. op. cit. p. 258.

(6) The right to a decent minimum of health care. Id. Ibid., p. 259-261.

(7) Forfeiting the right to health care. Id. Ibid., p. 262-264. 
Abordam também a questão do "mínimo decente" do ponto de vista de uma política global de saúde(8), para finalmente tratar de questões em torno da alocação, da fixação de prioridades e do racionamento sanitário( ${ }^{(9)}$.

Conquanto essa abordagem constitua uma sensibilização no contexto liberal ao problema do acesso, mitigando o individualismo dessa concepção, entende-se que a autonomia no provimento das próprias necessidades pela adequada cobertura securitária privada se torna inadequada em um contexto de acentuada desigualdade social, como sói ocorrer em termos globais ou em termos de realidades específicas nacionais ou regionais. Isso força a necessidade de assunção mais efetiva do cuidado em saúde pelas coletividades e pelos Estados.

Saliente-se que essa desigualdade, historicamente associada aos chamados "países subdesenvolvidos", tem, de maneira crescente, em razão da globalização, aflorado local e também internamente às denominadas "economias desenvolvidas". Trata-se de problema não-ignorado pelos autores do "Principles of Biomedical Ethics", já que tem se convertido em uma preocupação crescente nos Estados Unidos, conforme por eles atestado.

Não se pode entender, contudo, que haja diferenças de fundo, essenciais, em termos da análise, sob ponto de vista ético, entre a privação de acesso por falta de cobertura securitária e a privação de acesso por falta de políticas públicas adequadas, conforme sugerido por Beauchamp e Childress, no excerto transcrito no início desta seção.

É certo que o problema da desigualdade no acesso poderá se manifestar em diferentes intensidades e abrangências, dentro de uma mesma comunidade, entre distintas regiões do país e diversos países ou regiões do globo. A desigualdade sói estar associada, por um lado, às barreiras econômico-sociais de acesso a condições determinantes da saúde (saneamento, educação, moradia, etc.) e, por outro lado, às barreiras, de mesma natureza, ao próprio acesso às ações e serviços de saúde (campanhas educativas, serviços ambulatoriais ou hospitalares).

Entende-se que, em ambos os casos, há necessidade de alocação de recursos, embora sob mecanismos alocativos distintos. Refere-se aqui à despesa pública, em uma vertente, a publicista, encontrando seus limites no orçamento público; e à distribuição dos encargos do seguro privado, na outra vertente, a privatista, achando seus limites no preço e na própria higidez do mercado de seguro.

Em quaisquer das vertentes, alocar recursos para a atenção em saúde se torna de importância fundamental, em face de sua escassez e da necessidade de distribuir custos, pois o financiamento dessa atenção, diante

(8) Global health policy and the right to health. BEAUCHAMP, Tom L.; CHILDRESS, James F. op. cit. p. 264-267.

(9) Allocating, setting priorities, and rationing. Id. Ibid., p. 267-281. 
de seus altos custos, é, sempre, dependente de uma racionalidade securitária. Isto é, todos devem contribuir para que não todos utilizem simultaneamente. Assim, em certa lógica e extensão, e apenas nessa limitada extensão, é irrelevante que a cotização seja feita entre cidadãos/contribuintes ou entre cidadãos/consumidores.

A questão de fundo, no entender do presente estudo, segue sendo única e se traduz na racionalidade e na justiça da repartição dos encargos sociais do "seguro-saúde", amplo senso, ou seja, englobando tanto a seguridade social, de natureza legal e pública, quanto o seguro privadosaúde, de natureza contratual e objeto da atividade econômica privada ${ }^{(10)}$.

Quanto ao pensamento de Ronald Dworkin ${ }^{(11)}$, teve grande influência na discussão do tema uma palestra ministrada em 1993 na Universidade McGill, no Canadá. Nessa palestra o autor se opõe ao entendimento que denomina "modelo clássico ou do isolamento" da justiça sanitária, que descreve da seguinte maneira: 1) a saúde seria o bem mais importante do indivíduo; 2) o critério de sua distribuição seria do acesso pela necessidade, independentemente do custo; 3 ) isso implica para a sociedade a "regra do resgate", pela qual não se tolera que alguém venha a sofrer ou morrer quando se pode aliviar o sofrimento ou postergar a morte.

Em oposição a tal "modelo do isolamento", a teoria de Dworkin vai afirmar que: 1) há outros bens que competem com a saúde, como educação, segurança, previdência e assistência social; 2) o critério da necessidade se torna complexo em face da interpretação do que seja, de fato, uma necessidade; e, por último, 3) o critério do resgate choca-se com muitas das intuições sobre prioridades sanitárias (manutenção de enfermos terminais, chances de sobrevida, etc.).

Assim, seria ingênuo e, mesmo imoral, em um contexto inevitável de escassez de recursos, menosprezar os custos reais das decisões. Propõe, em contrapartida, um modelo de justiça sanitária derivada de sua teoria da igualdade de recursos.

Dworkin considera que, se os indivíduos fossem adquirir todas as prestações atinentes à atenção em saúde no mercado, adquirir-nas-iam não segundo um critério de necessidade, mas sim conforme um critério de prudência. O mercado obriga as pessoas a que se responsabilizem por suas escolhas. Se o acesso é igualitário (porque parte de condições iniciais igualitárias), então o resultado do escolhido pelas pessoas é moralmente justo.

(10) Para maior clareza, necessário é frisar que não se propugna tratar-se (a seguridade e o segurosaúde privado) de formas equivalentes, senão que similares, de distribuição de encargos. E que, por essa razão, para alguns efeitos, podem ser comparadas.

(11) DWORKIN, Ronald. Justice in the distribution of health care. McGill Law Journal, v. 38, n. 4, p. 883-898, 1993. 
O pacote que a média das pessoas compraria deveria determinar o que os sistemas sanitários públicos se encarregariam de marcar como limites do direito de atenção sanitária.

Pressupõe-se, nesse modelo, que algumas prestações ficariam excluídas da cobertura universal. Por exemplo: manutenção de vida vegetativa, intervenções em situação de demência, custos elevados para garantir poucas semanas de vida, doenças da velhice e tratamento muito custoso ou em relação às quais as pessoas não decidiriam investir a sua renda. Apesar disso, os tratamentos caros e pouco efetivos poderiam continuar disponíveis, adicionalmente, em um mercado privado de saúde.

O modelo proposto de Dworkin está sujeito a inúmeras críticas, em especial quando se consideram as dificuldades de ordem prática em sua eventual aplicação. Uma crítica contundente nesse sentido é feita por Ángel Puyol González, autor que será abordado mais adiante.

Lançado este olhar sobre o contexto do Estado Liberal, passar-se-á ao pensamento sobre o problema da alocação presente em países onde vigem sistemas público-universalistas de atenção à saúde.

\section{O ACESSO EM PAÍSES DE ATENÇÃO PÚBLICO-UNIVERSALISTA À SAÚDE (MARIA DO CÉU PATRÃO NEVES E ANGEL PUYOL GONZÁLEZ)}

Nesta seção serão analisadas as elaborações sobre o problema do acesso por dois autores radicados em países desenvolvidos onde, distintamente dos Estados Unidos, vigem sistemas públicos universalistas de atenção à saúde. Trata-se de Portugal e Espanha e do pensamento de Maria do Céu Patrão Neves e Ángel Puyol González respectivamente.

Maria do Céu Patrão Neves ${ }^{(12)}$, filósofa e professora da Universidade de Açores, reconhecia, já em 1999, que a alocação de recursos em saúde se constituía em uma das mais recentes e urgentes problemáticas para a bioética. Na oportunidade abordou o tema sob o aspecto da justiça e da responsabilidade moral, tratando-os nas perspectivas da fundamentação e da efetivação do direito à saúde.

Identifica a autora, com a exigência de intensificação da responsabilidade moral sobre a alocação de recursos em saúde, os princípios da: "dignidade humana" e da "participação". Por outro lado, reconhece, na perspectiva da efetivação do direito à saúde e da promoção da justiça social, a necessidade de considerar dois princípios outros: o da "equidade" e o da "solidariedade",

(12) NEVES, Maria do Céu Patrão. Alocação de recursos em saúde: considerações éticas. Bioética Revista do Conselho Federal de Medicina, v. 7, n. 2, 1999. Disponível em: <http://www.portalmedico.org.br/ revista/bio2v7/alocarec.htm>. Acesso em: 14 jul. 2008. 
sendo que, da ponderação desses quatro princípios, deveriam partir as construções visando às escolhas alocativas sanitárias.

Pondera Neves que a consideração ética, exclusivamente, fundamentaria a promoção de todas as ações de atenção em saúde possíveis, mas que o contexto da escassez implica a necessidade de "articular economia e ética", subordinando assim "os interesses monetários ao valor do homem".

No campo da responsabilidade moral, a autora alerta que há de ser transcendida a responsabilidade pensada por W. Frankena ${ }^{(13)}$, estritamente em termos de responsabilidade pessoal, como o dever de cuidar de si mesmo e, portanto, de sua própria saúde, influenciando, em um sentido prospectivo, seu estilo de vida e implicando, em um sentido retrospectivo, a imputabilidade ao indivíduo pela ação realizada em desconformidade com tal dever. Afasta tal modelo por considerá-lo reducionista e propugna, com base em Hans Jonas ${ }^{(14)}$, uma responsabilidade com dimensão coletiva. A responsabilidade a ser pensada no campo sanitário envolveria três diferentes níveis:

[...] deve responder por sua saúde no que ela depende de si, considerando as instituições que a financiam — responsabilidade pessoal; entre os indivíduos na sua existência comunitária, que devem reconhecer que a saúde não resulta de um processo puramente individual e é, hoje, um projeto social que exige o concurso de todos - responsabilidade social (cívica); nas relações do Estado com os indivíduos ou com a comunidade (que não corresponde meramente à inversa da primeira, numa relação recíproca), que deve assumir que este projeto social só poderá ser implementado por meio de um Sistema Nacional de Saúde, no cumprimento da missão dos governantes de proporcionar bem-estar aos cidadãos - responsabilidade política ou governativa. ${ }^{(15)}$ (grifo nosso)

Nesse contexto da responsabilidade, seguem as escolhas sendo inevitáveis, porém, mais que isso, passam a ser desejáveis. Desejáveis, porque ativam o princípio da responsabilidade moral em todos os níveis. Sintetiza Neves ${ }^{(16)}$ :

[...] diremos que a exigência da intensificação da responsabilidade moral, como contributo para a alocação dos recursos em saúde, fundamenta-se em dois princípios éticos - o da "dignidade humana" e o da "participação" - e se reporta a três aspectos principais (que respondem diretamente ao caráter triplo da responsabilidade moral): à adoção de comportamentos que promovam a saúde; à conscientização da finitude do homem e dos limites

(13) FRANKENA, William Klaas apud NEVES, Maria do Céu Patrão. op. cit.

(14) JONAS, Hans apud Id. Ibid.

(15) NEVES, Maria do Céu Patrão. op. cit.

(16) Id. Ibid. 
inerentes a toda a expressão humana; à realização de escolhas ponderadas. O princípio da dignidade humana, na exigência de igual respeito por todos os homens, e o princípio da participação, na exigência do esforço de cada um em prol da comunidade, justificam a ampla acepção do direito à saúde e obrigam à responsabilidade. (grifo nosso)

As escolhas mencionadas, reconhecidas como necessárias e desejáveis, apenas se justificam eticamente. Entretanto, segundo a autora, na perspectiva de promoção da justiça social: a realização do bem comum através da responsabilidade específica de cada um. Apesar de complexa, a noção de justiça implica, de modo fundamental, o princípio da equidade.

No domínio específico a que nos dedicamos, o princípio da equidade reporta-se ainda a uma aplicação casuística da justiça que, ratificando a igual dignidade de todos os homens, estabelece igual acessibilidade aos cuidados de saúde através de sua redistribuição diferenciada: isto é, atribuindo mais a quem tem menos e viceversa (vertical); e atribuindo o mesmo aos que se encontram em iguais condições (horizontal), numa ação anti-discriminatória, reguladora da desigualdade. ${ }^{(17)}$

A promoção da equidade nos termos anteriormente expostos vai reclamar o concurso do princípio da solidariedade, por sua vez assim descrito por Neves ${ }^{(18)}$ :

O princípio da solidariedade destaca uma realidade social que se refere à interdependência de todos os homens, de forma que cada um de nós é sempre devedor do outro em cada uma das suas realizações; reconhecido este fato no domínio específico da saúde [...], a solidariedade exige a partilha dos custos financeiros com a saúde de todos, proporcional ao rendimento de cada um. (grifo nosso)

Fecha-se assim a articulação entre os quatro princípios mencionados pela autora: o princípio da dignidade humana, o princípio da partição, o princípio da equidade e o princípio da solidariedade.

Patrão Neves reconhece que essas ponderações se encontrariam no patamar de uma metaética e de uma macroalocação de recursos, sendo necessário, para fins de aplicação, derivar diretrizes voltadas a orientar as escolhas e derivar critérios para a distribuição de recursos. Isso estaria no patamar de uma mesoalocação, mencionando como critérios mais presentes atualmente os da necessidade e da igualdade, que assumiriam, inclusive, pesos distintos a depender das características da sociedade que os utiliza. Segundo a autora, sobressaem-se a igualdade nos Estados Unidos e a necessidade na Europa.

Considere-se ainda que não se tem a pretensão, nem se deseja, que todos os problemas em nível de microalocação venham a ser resolvidos,

(17) NEVES, Maria do Céu Padrão. op. cit.

(18) Id. Ibid. 
satisfatoriamente, pela aplicação mecânica ou acrítica dos modelos desenhados, devendo esses ter sua validade testada e contestada no caso concreto.

Na Espanha, onde também vige um sistema de atenção pública universalista à saúde, o tema da escassez foi tratado por Ángel Puyol González ${ }^{(19)}$, professor e pesquisador em filosofia moral da Universidade Autônoma de Barcelona.

Este autor, reconhecendo a necessidade de racionamento sanitário em face da escassez de recursos, preocupa-se com os critérios que informariam uma escala de priorização da atenção a ser prestada, voltandose, portanto, a uma ética prática e finalista. Nessa busca de critérios, faz a análise dos argumentos alinhavados pela teoria utilitarista e formulados por Ronald Dworkin na forma aqui já descrita, propondo-se a sua crítica.

González inicia ponderando que a ideia central do utilitarismo é de que o bem social equivale à maximização da soma do bem-estar dos indivíduos, o que, no campo sanitário, equivaleria a maximizar a soma dos estados de saúde dos indivíduos. Assim, sistema sanitário justo seria aquele que consegue aumentar ao máximo a saúde somada de todos os cidadãos.

Nesse raciocínio, entretanto, ter-se-ia que quantificar estado de saúde, com base em um conceito de saúde, o que já constituiria um problema prático inicial não-desprezível. Num primeiro aspecto, o problema seria salvar vidas (com questões morais como a de admitir que algumas vidas serão sacrificadas em benefício de outras) e, depois, obter a melhor qualidade de vida (com o problema de como medi-la). Admite-se ainda que certas pessoas trocariam alguns anos de vida por uma melhor qualidade de vida e vice-versa, ou seja, adicionariam vida aos seus anos em vez de anos à sua vida.

Um índice utilizado para medir qualidade de vida é o Quality Adjusted Life Year (QALY), ou, em português, Anos de Vida Ajustado pela Qualidade $(A \vee A Q)^{(20)}$. O critério de otimização seria o da maximização do índice agregado, em face do custo envolvido, permitindo-se que se escolha, dentre as intervenções sanitárias possíveis, as que serão mais custo-efetivas em termos de qualidade de vida.

A crítica preliminar feita por Ángel Puyol González é de que critérios desse tipo sempre significam uma igualdade meramente formal segundo o critério do estado de saúde, não se levando em conta aspectos intervenientes,

(19) PUYOL GONZÁLEZ, Ángel. Ética, derechos y racionamiento sanitario. Doxa, n. 22, p. 580-605, 1999. Disponível em: <http://descargas.cervantesvirtual.com/servlet/SirveObras/12826207572393734198846/ cuaderno22/Doxa22_25.pdf>. Acesso em: 26 maio 2007.

(20) O QALY/AVAQ é o produto aritmético da expectativa de vida e a medida da qualidade de vida dos anos remanescentes. O QALY/AVAQ fornece um indicador para avaliar os benefícios oriundos de uma variedade de intervenções em termos de qualidade de vida e sobrevivência do paciente. (Disponível em: <http://www.economiadasaude.com.br/new/aaz.php?letra=Q>. Acesso em: 28 jun. 2008.) 
como capacidade econômica, condição social, etnia, sexo e idade. As teorias utilitaristas assim baseadas, na verdade, não são igualitárias e resultariam em discriminação dos pacientes mais graves, mais velhos, mais pobres ou menos capacitados, pois, em relação a estes, os ganhos não seriam comparáveis com os obtidos em referência ao indivíduo em condição diversa destas.

A teoria liberal-igualitária vai procurar privilegiar, é certo, a liberdade do cidadão e, portanto, a capacidade individual de pagamento, que, por um lado, dará a capacidade de acesso e, por outro lado, alocará de forma difusa os recursos sanitários na sociedade. O que pretende a teoria de Dworkin é fundamentar um princípio ético para o racionamento dos recursos sanitários no contexto liberal, de forma que o provimento da atenção pelo Estado será em medida tal que não contrarie o princípio da liberdade individual.

González critica tal proposta por considerar que esta levou muito longe a ideia de responsabilidade individual. Uma crítica inicial e geral a esse direcionamento é quanto à dificuldade de separar claramente preferências do indivíduo das circunstâncias em que estas são manifestadas. O fundamento dessa teoria de justiça é criticável ainda em seu ponto de partida, que é a igualdade de recursos, porque, de imediato, surgiria uma desigualdade na justificação do favorecimento dos mais ambiciosos e, logo, mais sacrificados, que por esse sacrifício deveriam receber maior prêmio.

No campo da justiça sanitária, o rechaço de Dworkin ao princípio da necessidade, entre outras razões, deve-se a que essa ideia de necessidade seria relativa a convicções éticas diferentes e não-comparáveis entre si. González, todavia, contrapõe que, se a falta de respeito ao neutralismo estatal sobre as convicções éticas de seus cidadãos pode conduzir ao autoritarismo, a ausência de um critério ético universalizador de mínimos com relação ao que se deve entender por necessidade médica pode lançar ao mais indiferente dos relativismos.

Feitas essas considerações de caráter geral, González passa às objeções particulares ao princípio da prudência defendido por Dworkin. Uma das consequências práticas da aplicação do princípio é a de que o sistema público de saúde deveria excluir de suas prestações, todas aquelas que um cidadão standard não compraria. Por outro lado, os gastos com saúde pública deveriam ser cobertos pelo conjunto da população, o que finda por discriminar os que se sacrificariam mais, objetivando maior cobertura, e assim financiariam a necessidade de atenção sanitária a quem, por eleição pessoal, sacrificou-se menos. O princípio da prudência acaba castigando a quem teria legítima vantagem segundo os cânones da igualdade de recursos.

O princípio da prudência consideraria imprudente custear com dinheiro público o tratamento de numerosas enfermidades minoritárias e que, atualmente, implicam altos custos devido, entre outras razões, ao baixo investimento em pesquisa. São enfermidades cuja pesquisa e atenção é 
recusada pela iniciativa privada, por tais atividades não resultarem lucrativas. Se tal situação é explicável ou justificável com base em uma racionalidade exclusivamente econômica, o mesmo não resultaria tão simples sob a perspectiva de uma racionalidade ética.

Acresça-se aqui que tal raciocínio não excluiria também algumas doenças de maiorias, como é o caso da malária. O cidadão-padrão do mundo ocidental não tem problemas graves com a malária. A indústria farmacológica deixou de lado a investigação nesse campo, porque os compradores potenciais das vacinas e dos medicamentos são tão pobres que não resultaria em um investimento economicamente rentável. A necessidade, eticamente sustentada, de uma intervenção pública ou estatal que reequilibre os interesses em jogo, forçosamente implica uma relativização dos princípios que o modelo de Dworkin visa preservar.

Se as enfermidades minoritárias ou não-rentáveis estão já claramente marginalizadas pela iniciativa privada, a negativa pública de sufragá-las em face do critério do cidadão-padrão(21) marginalizaria ainda mais os enfermos envolvidos e suas famílias, o que não parece ético, e tampouco justo, sob a perspectiva da igualdade de oportunidades.

González ainda considera o caso, no modelo dworkiano, do cidadãopadrão, o qual não se asseguraria contra as enfermidades da velhice que fossem muito caras e pouco efetivas, esperando que as políticas públicas também refletissem este seu raciocínio. O fato, por si, seria susceptível de atentar contra os princípios morais e constitucionais que consideram iguais os direitos básicos de todas as pessoas, independentemente da idade. Mas, além disso, pode parecer plausível que um indivíduo valore menos sua má saúde quando jovem que sua má saúde quando ancião, mas não parece tão claro que tenha a mesma intuição moral sobre o estado de saúde, por exemplo, de seus pais.

Pondera ainda González ser possível que o moribundo chegue a aceitar esse argumento por fidelidade a seus hipotéticos compromissos da juventude com o princípio da prudência e com uma espécie de princípio natural que consiste em dar preferência aos mais jovens. No entanto, não estará tão claro que estes estejam dispostos a deixar morrer seus familiares amparandose no mesmo argumento.

Ainda um argumento que comprometeria o princípio da prudência, nos moldes do modelo criticado, seria a necessidade de reconhecer como legítima a pretensão do cidadão que, por convicção ética, considerasse desproporcional o custo da atenção no que diz respeito aos benefícios que se lhe oferecem e que viesse a recusar tal atenção, na condição de se creditar dos valores monetários correspondentes.

Em síntese, o que Ángel Puyol González afirma é que, embora o direito à atenção sanitária deva ser revisado ou reinterpretado à luz da necessidade 
de priorizar, os critérios utilitaristas e liberais analisados apresentam vários inconvenientes éticos. Rechaça a interpretação exclusivamente utilitarista de que a atenção em saúde, em face de que o direito à saúde é, também, um direito individual e que saúde é moralmente importante porque afeta indivíduos, e não somente a coletividade. $\mathrm{O}$ utilitarismo geraria discriminações que afastariam o Direito de suas pretensões de equidade.

A proposta de Dworkin se equivoca, segundo o autor, especificamente, em seu intento de condicionar a equidade à responsabilidade individual. Em termos de necessidade sanitária, dificilmente se vê com disposição de calcular o valor exato que se concede à saúde antes de perdê-la e, em consequência, o que se está disposto a sacrificar para recuperá-la. Reconhece-se, todavia, que a discussão sobre a validez dos princípios que devem regular o racionamento sanitário não fez, até o presente momento, mais que começar.

Considera-se importante expor aqui a crítica de González à teoria utilitarista e liberal, pois nesta se põem a nu algumas falácias presentes na raiz de argumentos recorrentes na discussão sobre a alocação de recursos escassos. Por exemplo, a falácia presente na ideia de que os recursos poupados em determinada prestação sanitária estariam "melhor" empregados em outras, em favor da qual a reserva é agitada. $O$ argumento poderia estar, nesse caso, apenas mascarando uma alocação feita segundo critérios com teor semelhante aos aqui expostos, objetivando priorizar o hipotético cidadão-padrão e, no fundo, carecedora de uma maior reflexão racional e ética.

A crítica feita é ainda importante por confrontar visões liberais e "welfaristas" em contexto de países desenvolvidos, onde se pressupõe uma redução dos fatores de desigualdade entre os cidadãos, autorizando o favorecimento do princípio da autonomia perante o princípio da justiça.

Panorama distinto ocorrerá no contexto de países não-desenvolvidos, onde vicejam desigualdades mais severas e graves entre os cidadãos, determinando o enfoque que privilegie o princípio da justiça em face do princípio da autonomia.

\section{AMÉRICA LATINA, A POLITIZAÇÃO DA BIOÉTICA, A BIOÉTICA DA PROTEÇÃO E A BIOÉTICA DA INTERVENÇÃO (MIGUEL KOTTOW, FERMIN ROLAND SCHRAMM E VOLNEI GARRAFA)}

Na América Latina um dos enfoques que passa a ser adotado para contemplar o problema do acesso à saúde na reflexão bioética é o que propugna a aproximação entre a bioética e a política, no esforço de associar, aos problemas academicamente propostos pela bioética, o problema social sanitário em sua estreita relação com as condições socioeconômicas das populações envolvidas, a pobreza, a desigualdade e exclusão social. 
Têm-se as propostas da bioética da intervenção, formulada principalmente por Volnei Garrafa, professor da Cátedra Unesco de Bioética da UnB, e da bioética da proteção, formulada em especial por Miguel Kottow, professor da Universidade do Chile, e por Fermin Roland Schramm, professor da Escola Nacional de Saúde Pública (ENSP/Fiocruz), no Rio de Janeiro.

Antes, porém, deve-se atentar para uma discordância existente entre os autores quanto às relações necessárias entre política e bioética, discordância esta que determina a formação dessas duas propostas distintas, mas comunicantes.

Kottow ${ }^{(22)}$ se opõe a uma aproximação entre bioética e política. Defende o autor que ambas funcionam em âmbitos distintos; o ideário do poder é estranho ("foráneo") ao da bioética - possuem métodos diferentes. Portanto, a bioética não poderia adotar a linguagem do poder e não há como conceber uma convergência no campo da deliberação entre bioética e política. Isso porque a primeira se ocupa da "bios", existência, e a segunda da "zoe", a vida nua, ou seja, a vida animal, despojada de sua humanidade. O papel da bioética é precisamente o de proteger a "bios", para que não seja tratada como mera "zoe".

Kottow define a política como "[...] la administración, legítima, por lo general - del poder civil con fines de gobernabilidad"(23) e remete ao ensinamento de Max Weber ${ }^{(24)}$ e de Hannah Arendt ${ }^{(25)}$, que associam o exercício do poder ao da violência, legítima ou não, implicando, porém, sempre uma desigualdade ontológica entre o detentor do poder e aqueles que a ele se submetem ${ }^{(26)}$. A política, assim vista, possui escassa sensibilidade à elaboração ética. A bioética, ao contrário, de acordo com o autor, tem seu pensamento gravitando em torno da equidade e da comunicação. Isso significa dizer que política e bioética são imiscíveis.

Kottow não isenta nem mesmo a biopolítica, expressão forjada por Michel de Foucault para designar uma penetração, no campo das transformações políticas, da "vida e seus mecanismos". Para ele a biopolítica acaba por não passar de um extremo da violência política ao resumir a existência humana à vida biológica, polarizando e reduzindo os temas da bioética em dicotomias vida/liberdade. Nessa redução abstraem-se fatores

(21) Isto tanto em relação ao investimento em tratamentos atualmente disponíveis, muito caros e pouco efetivos, em uma ponderação exclusiva de rentabilidade econômica, como também em relação ao investimento em pesquisa científica, apta a, eventualmente, tornar tais tratamentos mais baratos, atrativos ou suportáveis nessa mesma perspectiva de rentabilidade puramente econômica. (22) KOTTOW, Miguel. Bioética y biopolítica. Revista da Sociedade Brasileira de Bioética, v. 1, n. 2, 2005.

(23) "[...] a administração, legítima, em geral, do poder civil com fins de governabilidade." (tradução nossa)

(24) WEBER, Max apud Miguel. KOTTOW, Miguel. op. cit.

(25) ARENDT, Hannah apud Id. Ibid.

(26) Id. Ibid., p. 111. 
culturais e históricos que diferenciam os integrantes de um grupo e os grupos entre si, em um "[...] discurso monocórdio que arrisca tornar-se intolerante e autoritário, eventualmente totalitário"(27). Sobre a contraposição bioética e biopolítica, expõe:

El discurso legal, no menos que el ético, queda marginado de participar en decisiones, silenciado en la crítica y desactivado en la práctica. Por lo tanto, la tendencia de la biopolítica a reducir a los pueblos y a los individuos a nuda pervivencia se sitúa en un nivel pre-moral, donde la bioética no tiene acceso porque su lenguaje se vuelve absurdo en situaciones límite: ¿cómo puede un principio bioético encontrar aplicación frente a la realidad de un campo de concentración $o$, en escenarios contemporáneos, tener vigencia cuando combatientes capturados no son considerados prisioneros de guerra y por ende no reciben el trato humanitario que internacionalmente se ha acordado? ${ }^{(28)}$

Repelindo a adoção de discurso ou de propostas políticas no âmbito bioético, afirma, entretanto, enfaticamente, a necessidade de uma bioética criativa cuja missão é reconhecer a necessidade do debate profundo sobre o impacto das eleições bioéticas no diário viver, repelindo a aparente simplificação do discurso biopolítico.

Tanto mayor ha de ser el esfuerzo de la bioética por detectar intrusiones morales en nuestras sociedades, que dicotomizan artificialmente los problemas en vida versus libertad, donde la biopolítica en ocasiones dará preferencia la vida sin importar su calidad, en otras a la libertad sin preocuparse para qué. ${ }^{(29)}$

Volnei Garrafa(30), por sua vez, propõe precisamente que a politização da bioética é incontornável se o objetivo é obter uma ética consistente voltada à garantia da dignidade da pessoa humana. A politização é necessária a fim de permitir a construção da justiça social. Considera que a inclusão social há de partir de conceitos como o de empoderamento, libertação e emancipação,

(27) KOTTOW, Miguel. op. cit. p. 114.

(28) "O discurso legal, não menos que o ético, fica marginalizado de participar em decisões, silenciado na crítica e desativado na prática. Portanto, a tendência da biopolítica em reduzir a população e os indivíduos à nua convivência se situa em um nível pré-moral, ao qual a bioética não tem acesso, porque sua linguagem se torna absurda em situações limites: Como pode um princípio bioético encontrar aplicação perante a realidade de um campo de concentração ou, em cenários contemporâneos, ter vigência quando combatentes capturados não são considerados prisioneiros de guerra e por isso não recebem o tratamento humanitário que foi internacionalmente acordado?" Id. Ibid., p. 116, tradução nossa.

(29) "Tanto maior há de ser o esforço da bioética para detectar intrusões morais em nossas sociedades, que dicotomizam artificialmente os problemas da vida versus a liberdade, em que a biopolítica dará, em umas ocasiões, preferência à vida, sem se importar com sua qualidade, em outras, à liberdade, sem se preocupar para quê." Id. Ibid., p. 119, tradução nossa.

(30) GARRAFA, Volnei. Inclusão social no contexto político da bioética. Revista Brasileira de Bioética, v. 1, n. 2, p 122-132, 2005. 
que constituem possíveis ferramentas epistemológicas do que denomina a bioética da intervenção, voltada, pois, a intervir no campo social.

Ainda segundo Garrafa, a resistência oferecida à proposta de politização da bioética em meios acadêmicos decorre, por um lado, do preciosismo que restringe o escopo epistemológico da disciplina, e está ligada aos prejuízos da dissociação entre razão e ação. Por outro lado, provém de um conservadorismo que impede o pesquisador de reconhecer que nem toda gama de conflitos éticos relacionados à vida e à saúde pode ser circunscrita ao âmbito biomédico.

Feito o alerta quanto a esses distintos posicionamentos, importa identificar as linhas em que normalmente se defende a inclusão na abordagem bioética dos elementos atinentes à questão social.

Kottow e Schramm ${ }^{(31)}$ propõem a bioética da proteção como uma esfera destinada a prover a proteção dos indivíduos marginalizados em uma ampla acepção e, portanto, susceptíveis ou fragilizados ao ponto de estarem impossibilitados de pleitear valores ou acautelar interesses, haja vista estarem ameaçados na sua "vida nua", aquém de todo direito ou da "participação cidadã."

Garrafa $^{(32)}$ coloca a bioética da intervenção nos seguintes termos:

Para a Bioética de Intervenção, a inclusão social é a ação cotidiana de pessoas concretas e precisa ser tomada na dimensão política, como um processo no qual os sujeitos sociais articulam sua ação. Na medida em que a ação cotidiana direciona as escolhas não apenas em função de uma inclinação pessoal, mas considerando a dimensão do todo - a necessidade de garantir a existência das pessoas e de todas as formas de vida - ela se torna inclusiva, tendendo, como decorrência, à maior simetria.

Cruz e Trindade ${ }^{(33)}$ aclaram a construção da proposta de uma bioética de intervenção fundada na impossibilidade de se cogitar da autonomia em um contexto no qual não haja possibilidades de escolhas livres.

Dessa forma, haveria que se trabalhar com os três conceitos de justiça social mencionados por Garrafa e aqui já referidos. Libertação, com base no pensamento de Paulo Freire, correspondendo à remoção de forças opressoras que impedem o exercício da autonomia, cerceada pela coação. Empoderamento "empowerment", fundamentado no pensamento de Amartya Sen, ligado ao fato de que escolhas autônomas não podem ser influenciadas

(31) KOTTOW, Miguel; SCHRAMM, Fermin Roland. Principios bioéticos en salud pública: limitaciones y propuestas. Cadernos de Saúde Pública, Rio de Janeiro, v. 17, n. 4, p. 949-956, jul./ago. 2001. (32) Id. Ibid., p. 129.

(33) CRUZ, Márcio Rojas da; TRINDADE, Etelvino de Souza. Bioética de intervenção: uma proposta epistemológica e uma necessidade para sociedades e grupos sociais vulneráveis. Revista Brasileira de Bioética, v. 2, n. 4, p. 483-500, 2006. 
pela falta de opções e designando precisamente a atribuição dos meios adequados às pessoas vulnerabilizadas para galgar o legítimo poder de decisão. E, por fim, emancipação, correspondendo ao suprimento da dependência, o que possibilita uma escolha independente. Assim, a inclusão social é fator de peso em uma bioética de intervenção, trazendo para a discussão bioética a dimensão política.

Resulta claro que a bioética da proteção e a da intervenção, em diferentes intensidades, propõem uma mitigação do princípio da autonomia para além das hipóteses clássicas e restritivas de vulnerabilidade ${ }^{(34)}$. Isso no sentido de se reconhecer uma esfera na qual a proteção dos indivíduos estaria fundada, precisamente, em situações de déficit de autonomia, geradas por vulnerabilidades adicionais, de natureza social, econômica ou biológica, impedientes do seu pleno exercício. Nas palavras de Garrafa ${ }^{(35)}$ :

A bioética da proteção foi pensada para proteger aqueles que, devido às suas condições de vida e/ou saúde, são vulneráveis ou fragilizados a ponto de não poder realizar suas potencialidades e projetos de vida moralmente legítimos, pois as políticas públicas de saúde não os garantem. Nesse sentido, a bioética da proteção é uma ética aplicada mínima ou "de primeiro nível" (como diz ATLAN), algo como uma condição necessária para que se possa dizer que estamos no campo da ética e para que os vulneráveis ou fragilizados tenham alguma possibilidade de viver dignamente e realizar seus projetos de vida razoáveis, compartilháveis com os demais.

Kottow e Schramm indicam a necessidade de uma ética específica para o tratamento dos temas de saúde pública. Aqui se está no campo das políticas públicas, no qual se trabalha com riscos e complicações de grande magnitude, de difícil mensuração e quantificação. Não se está trabalhando com situações individuais e pontuais, mas com grandes agregados, o que torna extremamente difícil fazer predições que possibilitem orientar moralmente, por via principialista, os comportamentos eticamente apropriados. Daí a necessidade de uma ética específica para a saúde pública(36).

Os autores analisam e criticam as possibilidades de sucesso de dois princípios propostos à análise ética da saúde pública: os da solidariedade e os da responsabilidade. Em relação ao primeiro, assim se pronunciam:

(34) As exceções ao princípio da autonomia em Beauchamp e Childress, por exemplo, ficam restritas às hipóteses de imaturidade ou incapacidade ("Young children, the severely retarded and senile patients"), por não haver intervenção apta a capacitar indivíduos nessa situação a tomar decisões autônomas. O conceito de vulnerabilidade é restritivo com o fim de evitar o paternalismo. BEAUCHAMP, Tom L.; CHILDRESS, James F. op. cit., p. 75.

(35) Id. Ibid., p. 147.

(36) O tema é tratado magistralmente por Giovanni Berlinguer: BERLINGUER, Giovanni. Ética da saúde. São Paulo: Hucitec, 1996. 
El principio de solidaridad se expone a innumerables críticas, sobre todo allí donde se le utiliza para legitimar políticas de asignación de recursos, que son reconocidamente finitos y escasos en cualquier sistema sanitario. El principio de solidaridad aplicado a las políticas públicas es insuficiente para resolver los complejos problemas de salud por estar obligado a ser solidario con los otros en situaciones de profunda diversidad de necesidades y aunque existan discrepancias profundas de valores que quedan opacas y negadas a la argumentación. ${ }^{(37)}$

Com relação ao princípio da responsabilidade, Kottow e Schramm analisam a aplicabilidade ao tema de uma ética da responsabilidade usando os modelos da responsabilidade ôntica de Hans Jonas e diacônica de Emmanuel Lévinas ${ }^{(38)}$. O entendimento, porém, é também pela sua insuficiência para tratar dos problemas éticos associados à saúde pública:

Estos tipos de responsabilidad indican que un agente moral debe ser responsable por las consecuencias de sus actos ante la sociedad y de acuerdo con normas validadas por una instancia evaluadora. En la práctica, no obstante, ello es difícil de realizar debido a las incertidumbres que afectan los cálculos probabilísticos utilizados en salud pública, como muestran prácticamente todos los estudios epidemiológicos [...]. ${ }^{(39)}$

Propõem então os autores uma ética da proteção considerando que a especificidade da reflexão bioética em saúde pública está em que tanto os agentes como os destinatários desta não são indivíduos, e sim instituições ou coletividades. O que se busca é um princípio capaz de promover o equilíbrio entre os interesses e os pontos de vista individuais e coletivos em torno do acesso à saúde. Kottow e Schramm afastam os princípios da solidariedade e da responsabilidade em duas dimensões, ôntica e diacônica, para esse fim e propõem, como princípio reitor dessa bioética preocupada com a realização do acesso em bases igualitárias, o princípio da proteção. Trata-se de um princípio dirigido pelos fins e resultados na atuação dos agentes morais em saúde pública.

Na proposta dos autores a ética da proteção recuperaria os conteúdos morais do princípio da responsabilidade, atualizando-os no sentido de

(37)"O princípio da solidariedade se expõe a inumeráveis críticas, sobretudo ali onde se lhe utiliza para legitimar políticas de atribuição de recursos, que são reconhecidamente finitos e escassos em qualquer sistema sanitário. O princípio da solidariedade aplicado às políticas públicas é insuficiente para resolver os complexos problemas da saúde por estar obrigado a ser solidário com os outros em situações de profunda diversidade de necessidades e a despeito de que existam discrepâncias profundas de valores que ficam opacas e inacessíveis à argumentação." KOTTOW, Miguel; SCHRAMM, Fermin Roland. op. cit. p. 951, tradução nossa.

(38)Id. Ibid., p. 951.

(39) "Estes tipos de responsabilidade indicam que um agente moral deve ser responsável pelas consequências de seus atos perante a sociedade e de acordo com normas validadas por uma instância avaliadora. Na prática, não obstante, são de difícil realização devido às incertezas que afetam os cálculos probabilísticos utilizados em saúde pública, como mostram praticamente todos os estudos epidemiológicos [...]." Id. Ibid., p. 953, tradução nossa. 
responder voluntariamente às necessidades dos outros e também no de se preocupar com a eficácia e a efetividade das medidas de proteção sanitária adotadas. Assim:

La evaluación puede mejor realizarse a partir de un principio de protección, el cual impone el deber de eficacia como condición necesaria para una potestad legítima de intervención, autorizada para exigir a la autonomía personal que se ajuste al bien común. ${ }^{(40)}$

Sobre as possibilidades de uma ética principialista na matéria do acesso à atenção em saúde, remete-se à abordagem de Maria do Céu Patrão Neves, exposta na seção 3.

Entende-se que nesta abordagem, como naquela, assoma-se como o grande desafio e o grande direcionamento a ser dado para a bioética na saúde pública o de transladar, com os necessários ajustes e modificações, a abordagem do nível das relações interpessoais, característico da bioética das situações emergentes, ao nível das relações institucionais e coletivas, característico da bioética das situações persistentes, conforme demonstram os autores latino-americanos cujo pensamento foi recém-exposto.

\section{CONSIDERAÇÕES FINAIS}

Os problemas atinentes à alocação de recursos em saúde, como constatado, não afligem unicamente países não-desenvolvidos. O agravamento do problema dos custos, associado que está à assunção de uma medicina tecnológica e aos fenômenos de transição demográfica e epidemiológica, é vivenciado, talvez em momentos e percepções ligeiramente distintos ou em maior ou menor extensão, em todas as regiões do globo, desenvolvidas ou não. Em poucas palavras, deve ser encarado como um problema global e comum a todos os países.

O surgimento de fatores de agravamento do problema do acesso à atenção em saúde é praticamente concorrente com a emergência da bioética como um campo de estudo. O desenvolvimento da biotecnologia, determinante histórico do surgimento da bioética, integra o fenômeno da tecnologização da medicina e, portanto, possui relação não somente com os problemas provenientes do acesso à atenção em saúde, mas também pode ter relação com as suas soluções.

Os caminhos assumidos por uma medicina biotecnológica importam à discussão bioética não somente na perspectiva da dignidade da pessoa

(40) "A avaliação pode melhor se realizar a partir de um princípio de proteção, o qual impõe o dever de eficácia como condição necessária para um legítimo poder de intervenção com autoridade para exigir, à autonomia pessoal, que se ajuste ao bem comum." KOTTOW, Miguel; SCHRAMM, Fermin Roland. op. cit. p. 955, tradução nossa. 
humana, individualmente considerada, como também na do desenvolvimento social-sanitário das coletividades humanas. As reflexões enfrentadas neste trabalho sugerem que a bioética, surgida nesse contexto, possui aptidão para ampliar e universalizar a discussão sobre a equidade no acesso, através da transcendência de algumas falsas dicotomias que vêm marcando a discussão, conforme referido no início do presente artigo.

Uma delas é a dicotomia que opõe modelos sociais e públicos de atenção a modelos liberais e privados de atenção à saúde. Uma evidência nesse sentido está em que, cada vez mais, se torna raro, senão impossível, encontrar sistemas reais que sejam puramente públicos ou puramente privados. A regra é a combinação dos dois sistemas, de modo eventual, com predomínio de um ou outro.

Outra evidência é a de que os fundamentos de um e outro sistema possuem pontos de superposição, não sendo absolutamente independentes. Corrobora esta assertiva a lógica securitária que preside a racionalidade econômica tanto em um quanto em outro sistema e a presença do vetor equidade que dirigem critérios alocativos em ambos, muito embora sob distintas concepções: ora como igualdade de oportunidades em um sistema de livre acesso, ora como igualdade substancial nas condições de acesso.

Outra dicotomia passível de relativização é a existente entre a bioética das situações emergentes e a bioética das situações persistentes. Uma evidência nesse sentido é a de que as barreiras ao acesso de natureza socioeconômica, presentes em quaisquer países em diferentes intensidades, embora possivelmente mais significativas e importantes, não são as únicas, pois há outros fatores que geram a discriminação no acesso, como a origem ou natureza dos agravos e as características da população a eles submetida, como idade, sexo, raça. Concorrem muitas vezes, na constituição de tais barreiras, preconceitos de ordem moral, cultural ou histórica, presentes em qualquer sociedade; razão pela qual o problema do acesso à atenção em saúde deve ganhar, na discussão bioética, os foros de uma discussão global, condizente com a vocação desse campo de estudo.

As buscas por respostas ao problema do acesso igualitário à atenção em saúde, tanto em uma perspectiva de fundamentação deontológica como em uma perspectiva de fundamentação teleológica, parecem enfatizar, em geral, a necessidade de que se adicione maior peso à questão da solidariedade social e da responsabilidade individual no uso racional de recursos sanitários em quaisquer dos modelos de alocação de recursos ou em quaisquer dos sistemas utilizados para o seu financiamento.

Trata-se de responsabilidade a ser pensada, concomitantemente, em relação ao indivíduo, bem como à sociedade e ao Estado. Autonomia e proteção são princípios a serem reequilibrados, enfatizando-se a necessidade 
de consideração de uma justiça distributiva a qual implicará, de maneira forçosa, a renúncia a cuidados e atenções não-universalizáveis sob critérios racionais e perspectiva substancialmente igualitária.

Nesse âmbito, a reflexão bioética deve incorporar e abranger os argumentos de ordem econômica, financeira ou orçamentária, a fim de que estes, recebendo carga axiológica, não se prestem a mascarar a assunção de prioridades eticamente não-defensáveis.

Entende-se que o direito, como disciplina a reger a intersubjetividade humana, possui um importante papel a desempenhar na tarefa. E, nesse escopo, princípios e institutos hão de ser modelados ou remodelados. Podem, eventualmente, migrar entre os distintos campos do conhecimento humano, promovendo-se a aproximação entre direito e bioética a fim de se permitir, ao primeiro, a apreensão dos fatos e valores que devem informar a alocação ética e justa de recursos sanitários escassos e, ao segundo, a instrumentalização de uma efetiva intervenção no campo social.

\section{REFERÊNCIAS BIBLIOGRÁFICAS}

BEAUCHAMP, Tom L.; CHILDRESS, James F. Principles of biomedical ethics. 6th ed. New York: Oxford University Press, 2009.

BERGEL, Salvador Darío. Bioética y el derecho de acceso a los medicamentos. Revista de Direito Sanitário, São Paulo, v. 7, n. 1-3, p. 117-162, 2006.

BERLINGUER, Giovanni. Ética da saúde. Tradução de Shirley Morales Gonçalves. São Paulo: Hucitec, 1996.

CRUZ, Márcio Rojas da; TRINDADE, Etelvino de Souza. Bioética de intervenção: uma proposta epistemológica e uma necessidade para sociedades e grupos sociais vulneráveis. Revista Brasileira de Bioética, v. 2, n. 4, p. 483-500, 2006.

DWORKIN, Ronald. Justice in the distribution of health care. McGill Law Journal, v. 38, n. 4, p. 883-898, 1993.

GARRAFA, Volnei. Inclusão social no contexto político da bioética. Revista Brasileira de Bioética, v. 1, n. 2, p. 122-132, 2005.

; KOTTOW, Miguel; SAADA, Alya (Coord.). Bases conceituais da bioética: enfoque latino-americano. São Paulo: Gaia, 2006.

KOTTOW, Miguel. Bioética y biopolítica. Revista da Sociedade Brasileira de Bioética, v. 1, n. 2, 2005.

; SCHRAMM, Fermin Roland. Principios bioéticos en salud pública: limitaciones y propuestas. Cadernos de Saúde Pública, Rio de Janeiro, v. 17, n. 4, p. 949-956, jul.-ago. 2001. 
NEVES, Maria do Céu Patrão. Alocação de recursos em saúde: considerações éticas. Bioética - Revista do Conselho Federal de Medicina, v. 7, n. 2, 1999. Disponível em: <http://www.portalmedico.org.br/revista/bio2v7/alocarec.htm>. Acesso em: 14 jul. 2008.

PUYOL GONZÁLEZ, Ángel. Ética, derechos y racionamiento sanitario. Doxa, n. 22, p. 580-605, 1999. Disponível em: <http://descargas.cervantesvirtual.com/ servlet/SirveObras/12826207572393734198846/cuaderno22/ Doxa22_25.pdf>. Acesso em: 26 maio 2007. 